\title{
Reflecting on Reflecting: Scholarship of Teaching and Learning as a Tool to Evaluate Contemplative Pedagogies
}

\author{
Alexis T. Franzese \\ Elon University, afranzese@elon.edu \\ Peter Felten \\ Elon University, NC, USA, pfelten@elon.edu
}

Follow this and additional works at: https://digitalcommons.georgiasouthern.edu/ij-sotl

\section{Recommended Citation}

Franzese, Alexis T. and Felten, Peter (2017) "Reflecting on Reflecting: Scholarship of Teaching and Learning as a Tool to Evaluate Contemplative Pedagogies," International Journal for the Scholarship of Teaching and Learning: Vol. 11: No. 1, Article 8.

Available at: https://doi.org/10.20429/ijsotl.2017.110108 


\title{
Reflecting on Reflecting: Scholarship of Teaching and Learning as a Tool to Evaluate Contemplative Pedagogies
}

\begin{abstract}
Although interest in contemplative pedagogies has grown considerably in higher education, faculty have relatively few resources available to help them make evidence-based choices about the use of different contemplative pedagogies in particular disciplinary or course contexts. We propose adapting a framework from the Scholarship of Teaching and Learning (SoTL) to serve as a heuristic for assessment of the design and implementation of these practices. After outlining this framework, we provide concrete examples from undergraduate courses to explore how a SoTL-informed design, implementation, and assessment process could be applied to the utilization of contemplative pedagogies. The examples suggest that there are many ways in which practices can be incorporated in support of deepening student learning and creating transformative learning opportunities for our students. We conclude with reflections on the potential and the limitations of this approach.
\end{abstract}

\section{Keywords}

contemplative pedagogy, SoTL, higher education, mindfulness, transformative education

\section{Creative Commons License}

cc) (i) $\Theta \Theta$

This work is licensed under a Creative Commons Attribution-Noncommercial-No Derivative Works 4.0 License. 
IJ-SoTL, Vol. 11 [2017], No. 1, Art. 8

\title{
Reflecting on reflecting: Scholarship of teaching and learning as a tool to evaluate contemplative pedagogies
}

\author{
Alexis T. Franzese' and Peter Felten ${ }^{2}$ \\ 'Department of Sociology and Anthropology, Elon University, Elon, NC 27244, USA \\ ${ }^{2}$ Center for Engaged Learning, Elon University, Elon, NC 27244, USA
}

(Received 29 April 2016;Accepted 19 August 2016)

\begin{abstract}
Although interest in contemplative pedagogies has grown considerably in higher education, faculty have relatively few resources available to help them make evidence-based choices about the use of different contemplative pedagogies in particular disciplinary or course contexts. We propose adapting a framework from the Scholarship of Teaching and Learning (SoTL) to serve as a heuristic for assessment of the design and implementation of these practices. After outlining this framework, we provide concrete examples from undergraduate courses to explore how a SoTL-informed design, implementation, and assessment process could be applied to the utilization of contemplative pedagogies. The examples suggest that there are many ways in which practices can be incorporated in support of deepening student learning and creating transformative learning opportunities for our students. We conclude with reflections on the potential and the limitations of this approach.
\end{abstract}

\section{INTRODUCTION}

"Integration and wholeness in student life is too important to be left to chance. It should be one of the guiding motives of higher education" (Zajonc, in Palmer, Zajonc, \& Scribner, 2010, p.56).

The growing interest in contemplative pedagogies around the world demonstrates that many higher education faculty are heeding Zajonc's call (e.g., Barbezat \& Bush, 2014; Gunnlaugson, Sarath, Scott, \& Bai, 20I4; Miller, 20I5; Oberski, Murray, Goldblatt, \& DePlacido, 20I4). These pedagogies build on three foundations: (I) contemplative practices that often have long, deep histories; (2) emerging research on the positive outcomes of contemplative practice for well-being and flourishing; and (3) scholarly studies of student learning in higher education (Morgan, 20I5). While those foundations provide a firm grounding for contemplative pedagogies in general, they do not offer specific evidence that would help faculty (or others) make judgments about the use of contemplative pedagogies in particular disciplinary or institutional contexts - nor do they point the way toward effective practices for determining student learning and development linked to contemplative pedagogies.

Questions about how to gauge the outcomes of these pedagogies, however, have received little attention in the literature to date (Coburn et al., 20I I; Glisczinski, 2007). Indeed, faculty, staff, and students who use contemplative pedagogies might wonder whether the complexities and richness of non-cognitive learning can rigorously be captured, measured, and evaluated. In a recent review essay on "Assessing Personal Qualities Other Than Cognitive Ability for Educational Purposes," Angela Duckworth and David Yeager concede that "perfectly unbiased, unfakeable, and error-free measures are an ideal, not a reality" (20I5, p. 243). Recognizing this limitation, Duckworth and Yeager contend that the purpose of most educational inquiries is not scientific validity but rather the improvement of practice.This argument aligns with what other scholars refer to as consequential validity. According to Pat Hutchings, Jillian Kinzie, and George Kuh, "Consequential validity posits that assessment must be valid for the purposes which it is used, consistent with relevant professional standards, and - this is the key point here - that the impacts or consequences of its use should be factors in determining its validity" $(2015,4 I)$. In short, efforts to understand educational outcomes need not meet the highest standards of experimental research in order to have merit and value. Instead, a fundamental criterion for any inquiry practice related to contemplative pedagogies is how useful it is to the faculty, staff, and students who design and enact contemplative pedagogies in their own classrooms.

Even if these methodological concerns can be addressed, some might still ask about the possibility, or even the wisdom, of applying the academic tools to the study of contemplative pedagogies (Baugher, 20I4). Critical inquiry often involves breaking down complex phenomena into discrete and depersonalized parts that can be measured and judged, while contemplative pedagogies focus on wholeness, synthesis, and self-knowledge (Barbezat \& Bush, 20l4). Is there an inherent, perhaps unbridgeable, chasm between the scholarly analysis and contemplation? We do not think so. For instance, the mindfulness-based stress reduction (MBSR) movement in medicine and health offers one successful model for the systematic study of how best to design, implement, and evaluate contemplative practices in specific learning environments (see Wilson, 2014 for historical review). The MBSR movement, which can be traced to the transformational writings of Jon Kabat-Zinn (and gained momentum with the publication of his 1990 book Full Catastrophe Living), began when a small number of providers decided to return to ancient wisdom about the mind-body connection. As in academia, teacher intention alone was a necessary but not sufficient condition for the successful implementation of these practices. As the MBSR movement began to grow and prosper, medical researchers used existing disciplinary methods to study the practices and outcomes of diverse MBSR approaches (Praissman, 2008). The now extensive literature on MBSR demonstrates that contemplative practices can be appraised with discipline- and use-specific methods without compromising the purposes of mindfulness. Meta-analyses conducted of the expansive MBSR literature consistently demonstrate its many benefits for health and well-being (Chiesa \& Seretti, 2009; Grossman, Niemann, Schmidt \& 
Walach, 2004). Indeed, systematic inquiry into outcomes did not compromise the aims of MBSR, but actually opened the door to compromise the aims of MBSR, but actually opened the
wider and deeper use of these practices in health care.

Academia now finds itself in a position similar to that of the medical community before the MBSR studies. Many in higher education are returning to the ancient wisdom that contemplatio and mindfulness are powerful, even essential, for deep and transformative learning. However, we have yet determined how to systematically, meaningfully, and sustainably design, implement, and evaluate mindful and contemplative pedagogies in higher education classrooms. The purpose of this article as to provide a practica approach for designing, implementing, and even studying the resuls of, contemplative practice guided by the Scholarship of Teaching and Learning (SoTL) framework. By demonstrating that SoTL is one useful way to examine the implementation and outcomes of contemplative pedagogies, we hope to spark additional research on contemplative pedagogies - research that can help all of us to make more evidence-informed and mindul pedagogical choices that will contribute to student transformation.

\section{CONTEMPLATIVE PEDAGOGIES AND THE} SCHOLARSHIP OF TEACHING AND LEARNING Incorporating contemplative pedagogies into one's teaching to purpose. The design, and ind begin with careful attention

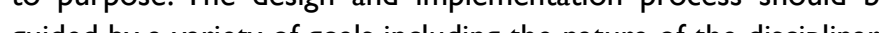
work, the faculty member's personal preferences and strength in contemplative practices, and the extent to which the ability to capture and measure outcomes is important. For practitioners who aim to understand the processes and results of contemplative pedagogies, the Scholarship of Teaching and Learning (SoTL) is a particularly helpful tool. SoTL is most simply defined as "a kind of 'going meta', in which faculty frame and systematically investigate questions related to student learning - the conditions under which it occurs, what it looks like, how to deepen it, and so forth-and do so with an eye not only to improving their own classroom but to advancing practice beyond it" (Hutchings \& Shulman, 1999). SoTL in action can be quite diverse, taking as assets the disciplinary training and research methodologies of the faculty members who are
conducting the inquiry.Across this diversity, however, Felten (2013) conducting the inquiry.Across this diversity, however, Felten $(2013)$
has identified five common principles that guide SoTL practice. We has identified five common principles that guide SoTL practice. We
have adapted these as a framework for the design, implementation have adapted these as a framework for the

I. Inquiry focused on student learning: What, how, and
Why why students learn varies widely across disciplines and courses. When inquiring into learning in a contemplative chench student' facts of the particular focus, learning should be at the center of

any inquiry into contemplative pedagogies.
2. Grounded in context: SoTL inquiry should be rooted in 2. Grounded in context. So Thecific context; we are not asking abstract questions about generic students, but rather we are seeking insight into the learning of these students, in this course, and on this campus. At the same time, SoTL inquiry should build on the scholarly context of our work. Researchers and practitioners have provided a strong foundation for both contemplative pedagogies (e.g., Barbezat \& Bush, 2014) and student learning in higher education (e.g.,. Ambrose, Bridges, DiPietro, Lovett, \& Norman, 2010), and any scholarly study should build on what is known. 3. Methodologically sound: Like contemplative pedagogies, SoTL is methodologically diverse, allowing faculty from range of disciplines to bring their own scholarly trainin and personal wisdom to bear on questions of student learning (Huber \& Morreale, 2002). Some disciplinary tools might be particularly apt for certain inquiries, such as positive psychology techniques for evaluating curiosity or mindfulness, but intentional application of many different research methods, including deeply introspective ones (e.g.g., Baugher, 2014), are sound when connected to the heart of a particular inquiry (McKinney, 2013). 4. Conducted in partnership with students: SOTL should be done with students, not to them. In practice this involve inviting students to join us in seeking to understand how individuals and the class community experience and lear from contemplative pedagogies. Such radical opennes can be and care chsrooms cal becoms bies for palence Healey, Flint, \& Harrington, 2014).

5. Appropriately public: As contemplative pedasogies 5. Appropriately public: As contemplative pedagogies - and students - will benefit if we trent our teaching as "community property" (Shulman, 2004). Going public with SoTL inquiries does not necessarily require publication in peer-reviewed journalss instead, many opportunities exist to share with and learn from colleagues on and beyond our campuses. By being public about the practices we use and the insights we gain, we are generously allowing others to adapt and build on our own learning from contemplative pedagogies.

These principles can act as a heuristic, a simple but useful guide, for faculty seeking to incorporate new pedagogical approaches into their teaching and to conduct classroom-level practical inquiry int learning and development linked to contemplative pedagogies. The this framework as a rellective guide

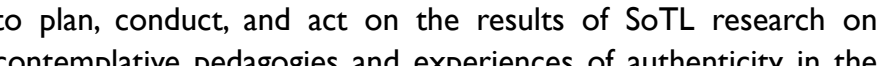
classroom (c.f., Dencev \& Collister, 2010 and Vannini \& Franzese, 2008 and Franzese, 2009 for discussion of authenticity.

To illustrate how this might be done, we will consider the ways one of the authors (Franzese, assistant professor of sociology at Elon University) has designed, implemented, and inquired into using the five principles outlined above. This case does not seek to revel how reflection affects students' performance in terns of course grades or students' ability to retain and apply disciplinary knowledge; instead, this example focuses on the primary concern of Franzese, frameworks, how contemplative pedagogies affect the in-the-moment classroom experiences of students. Franzese has brought contemplative pedagogies into the full range of courses she teaches, adapting her teaching practices to meet the needs of the students in each course. For instance, in her senior seminar
Franzese invited students to do introspective self check-ins at the beginning of each class meeting, and in her introductory course she asked students to participate in contemplative freewriting practice, and in her upper-level course she engaged the students with interest or expertise to lead the practice (See Table 1). Examples from each of these three types of courses are offered here to demonstrate the multitude of ways in which contemplative the SoTL framework.

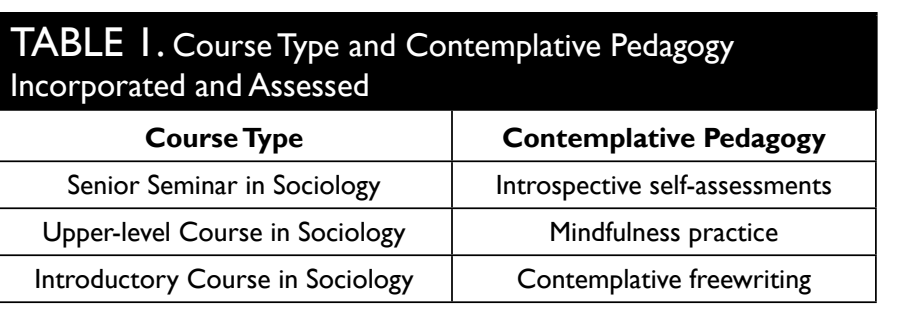

We do not offer Franzese's work as the only or the best way to enact and evaluate contemplative pedagogies. Instead, we describe her work to illustrate the flex bily and utility of using the Scholarship of Teaching and Learning to design and analyze Franzese making her own teching and inquines " "ppropritely public."

Inquiry Focused on Student Learning

In each course, she had three common goals for contemplative pedagogies:

(I) To invite students to be fully present, including allowing students to gauge their emotional reaction and response to

(2) To facilitate a sense of connectedness and invoke a sense of membership in a learning community, and

(3) To develop a reflective process orientation toward disciplinary learning, rather than focusing primarily on

products and outcomes.

Her choices of specific contemplative practices aligned with her goals for students' learning in each course. For her senior seminar course in Sociology she selected introspective self-assessments
as the contemplative practice. With the pedagogical practice of as the contemplative practice. With the pedagogical practice of
introspective self-check-ins, she hoped students would gain (a) selfawareness/sense of authentic experience, (b) compassion for self hinder their ability to comote These check-ins provided time for reflection and normalized the process of thinking about one's experience in a given setting The contemplative practice for her upper-level sociology course was a mindfulness practice at the beginning of class that she intended for students to (a) gain skills for focusing their attention. (b) be in a state of openness about different ways of seeing the world. (c) focus more acutely on disciplinary content. Finally, in her Introduction to Sociology course she used the contemplative practice of freewriting to help students (a) gain insight and compassion, (b) think critically and deeply about disciplinary content.
Linking to the SoTL framework, each of the pedagogies generated some evidence of student learning that gave both the students and Professor some insight into the experiences of student learning. Indeed, the Franzese's SoTL-inspired inquiries into the first place.

Grounded in Context

As Franzese planned for the ways contemplative pedagogies would be woven into her teaching, she thought carefully about her educational institution, students, her discipline, the purposes of each course, and the range of contemplative pedagogies that might help her students toward her goals.

Franzese teaches at Elon University, a private and selective liberal arts institution in Elon that enrolls roughly 5,500 undergraduates. Elon students tend to come from the eastern half of the United States, and many grow up in middle class or upper class families. Prior to her courses, few have actively engaged least a passing familiarity with mindfuness, yogat many have at and a few sing tant and a few students ( $1-2$ per class in the upper level courses) had an of the 25 students in the class typically are not Sociology majors. so they have little or no famility with the theories and metods of the discipline. In the senior seminar, all students (typically 8-10) are majors and have developed some disciplinary knowledge and expertise in prior courses, although they probably have not experienced contemplative pedagogies before.

The introspective self-assessments she designed for her senior seminar course were selected in consideration of the demands of the course. As the capstone course for majors, senior seminar students are required to complete a full research project - from development of a research question to gaining approval to conduct human subjects research, collecting and analyzing data, and finally presenting the project to an audience. In addition to these demands, students are also required to engage in professional development tasks such as resume writing and preparation of job application or graduate school materials. Because of the extensive demands of the course - and the short window of time allotted (a mere semester!) - anxiety and negative anticipation have historically been high among students. With this expectation, Franzese opened classes with a 2-5 minute introspective check-in. At the beginning put their heads down and raised their hands responsively as Franzese listed varying levels of concern and negative anticipation. influenced by the responses of their peers. After the chss enged in this activity Franzesenses of their peers. After the class engaged eported by the students. This feedback aimed to normalize the wory and negetive anticipation when those felings suffed and to highlight the elation and relief when those were prominent sentiments. This brief exercise afforded students the opportunity to realize that they were not alone in their experiences. Additionally, on days where levels of distress were high, once students knew that others were distressed as well they typically were willing to solve and 
own confidence in their abilities. An advantage of doing this over the course of the semester was that it also demonstrated to the
students that levels of concern (or lack of concern) are oscillatingstudents that levels of concern (or lack of concern) are oscillating-
that even when we are most concerned or overwhelmed, these
times are followed by times when we feel efficacious and in control. times are followed by times when we feel efficacious and in contro productively with emotions and focus on their disciplinary work. A by-product of this practice was that students felt bonded to one another - multiple students remarked in their feedback forms about the great extent to which our class was a supportive learning
community. At the final research presentations students requested a group photo of the class, illustrating just how supportive students were over the course of the semester and how invested they seemed in the projects of others. In addition, multiple students referred positively to the check-ins when feedback was invited a the end of the semester.

The mindfulness practices Franzese designed for her upperlevel sociology course (which included disciplinary content focusing on the self), again were selected in response to contextual factors. Since the course was taught in the spring semester at lunchtime and was comprised primarly of juniors and seniors, Franzese engaged during the course. Students often are distracted and as engaged during the course. Students often are distracted and as think (see Forni 2011 for discussion). With this in mind, Franzese shared information about mindfuness practices with the students and asked them if they might be willing to begin each class with a mindfulness practice. She explained that while mindfulness has connections to Eastern religious traditions that the practices we would be doing were not affiliated with any religious tradition would be doing were not afflitated with any religious tradition consented verbally to engage in the first practice. She continued to request consent prior to conducting any mindfulness practices.
However, after approximately $3-5$ classes, students would request a mindfulness practice as soon as she entered the classroom. The mindfulness practices we engaged in ranged from meditation on counting one's breath to body scans, to sending good wishes, to mindfully listening to a piece of music. The purpose of the practices was to teach students skills to increase awareness so that they could have an increased level of attentiveness while learning in the class session. Again, an enhanced sense of connectedness was a byproduct of the practice and students shared feedback about
this benefit of the practice verbally throughout the course. Most this benefit of the practice verbally throughout the course. Most
striking was the way in which students would begin statements striking was the way in which students would begin statements
with the phrase "I can say this here because this class is safe/ with the phrase "I can say this here because this class is safe/
close/comfortable different..." followed by a statement that that a student may feel too vulnerable or inhibited from exploring or a student may feel too vulting

primarily of first and second $y$ to Sociology course, comprised contemplative practice that matched the contextual de seleced year of students) but also was explicitly and specifically related to the sociology disciplinary process. The professor tells students that what distinguishes a sociologist from someone who is curious that what distinguishes a sociologist from someone who is curious phenomena. Because she wanted students to develop a familiarity the social world - she used a contemplative approach that focuses on process, freewriting (Barbezat \& Bush, 2014). The course regularly deals with controversial themes about race and ethnicity, socioeconomic status, crime and deviance, reproductive rights, and in Franzese's courses typically were initially reserved in classroom discussions. For this reason, she developed a contemplative freewriting practice in which students had the opportunity to express themselves in an unfiltered way about their reactions to a reading or discussion topic, or to respond to questions the professor posed about the reading or theme. The instructions for the freewriting stated that the purpose of the writing was not com provide them a time and space in which they could discover or own reactions. They were directed not to edit for grammar or spelling but to write continuously from the time they were end of the semester students time they were told to stop. At the they reflect on their freewriting process. Franzese offered this the in their freewriting thinking about my reading their writing. She 作 of to learning can occur.

Linking to the SoTL framework, the practices that Franzese selected were an appropriate and reasonable fit for Franzese's discipline and interest in authenticity, specific courses, and academic institution. Across classes, Franzese, often also invites students to include a "Personal Reflections" section at the end of research papers, which again legitimizes the activity of reflection and allows students to think reflectively about the work they have completed. The type of contemplative practices utilized and the analysis of specific course goals and objectives.

\section{METHODOLOGICALLY SOUND}

Franzese's design and implementation of the contemplative practices was methodologically sound in that the process was informed by extensive reading on these topics and in consultation with peers both within and beyond her university. Her analysis of its outcomes was also methodologically sound and appropriate because it was related to her inquiry, it provided relevant and France evententially valid.

Franzese's fundamental question was, do contemplative practices deepen student engagement and student learning? To appear engaged? Did they arrive on time? Were absences few? Second, she looked to students' report of their own engagement and learning. Finally, she looked to student disciplinary content, both acquisition and retention of course

Franzese routinely gathers student feedback at various points in the semester. While students are informally invited to share feedback at any time, she officially collects feedback halfway through the course by providing students with a mid-semester
evaluation form. The form has only a few questions including versions of: "what's working!" and "what do you want to see changed?" At the end of the semester, to capture student perceptions of these contemplative practices, Franzese added a question to her University's standard Student Perceptions of Teaching (SPOT) forms
that asked precisely that; for example, in her upper level course she that asked precisely that; for example, in her upper level course she
asked whether students felt that contemplative practices enhanced their learning. Students responded to the question on a six-point scale from Strongly Disagree (or a " 1 ") to Strongly Agree (a " 6 "). In her upper-level seminar, the mean response on this item was 5.44, meaning that nearly all students "agree" or "strongly agree" that the that course (and in others which utilized contemplative practices) about the extent to which students felt safe (an important question since Franzese often articulates to students that it is acceptable to her that they feel uncomfortable but essential that they feel safe). The score on that item was 5.88 (while for the Introductory course it was 5.26 and for the senior seminar course a 6 , meaning that every
single student reported feeling very safe in the course). The SPoT single student reported feeling very safe in the course). The SPoT
form also includes space for students to write comments related to form also includes space for students to write comments related to each prompt, which included qualitative responses ". "

Franzese's analysis of the students' freewrites and summaries
" provided evidence of the raw and reflective products of her contemplative pedagogy. She focused her evaluation to this writing engagement with key themes from course readings, (b) the extent to which students linked course themes with themes in the readings, and (c) the degree to which students' writing displayed introspective consideration related to key topics. Analysis of these freewrites revealed that students were making linkages across course readings and were relating the course material to their own life experiences, often resulting in more informed perspective. The analysis of the freewrites was a reflective process for Franzese as well, resulting in a list of topics to be explored and utilized with students in future semesters. This example of direct evidence of student learning
allowed her to address how effective the contemplative pedagogical practice was meeting her general goals of present-moment awareness, connectedness, and process orientation as well as my course specific goals of insight/compassion, courage in addressing challenging themes, and critical thinking about disciplinary conten

Linking to the SoTL framework, Franzese selected practices that disciplinary expertise to the study of contemplative practices.

Conducted in Partnership with Students

As illustrated above, Franzese approaches contemplative pedagogies as invitational - something she invites students to do, not a requirement. fromer. them.

For instance, in her senior seminar, Franzese opened most classes with a heads down, hands up assessment of how students were feeling at the start of each class. This practice welcomed students to engage in three distinct contemplative acts. First, students had the
task of checking-in with themselves--how were they feeling? Second students had the opportunity to decide whether or not they wanted to share this information, a practice of vulnerability and trust and selfcompassion involved in disclosure. Third, students engaged in the act of responding to the feedback provided to the class about how others were feeling which appeared to increase both self-acceptance and compassion for others. All of these acts were offered by invitation and students could decline to participate in these practices as they were comfortable She would also do a more holistic check-in at the beginning of class-- touching base not only about the status of projects but also of individual struggles. This facilitated a sense of inviting students to be present, she actually served to facilitate her second goal of creating a learning community. In addition to these check-ins at the beginning of class, she would also from time to time o these quick check-ins when the class discussed due dates for The compor

This sense of a learning community was pursued in a different way in the context of her upper level seminar course as well as in We seminar, knowing the names of peers may be easy and common, courses in her courses. This exercise, which Franzese adapted from an activity she participated in at an Anti-Defamation League workshop and circles are tormed in which partic circles," is an activity in which two is posed, and then one circle rotates so that individha a question is posed, and then one circle rotales so that indivdals are face to intial exercise learning circles are often a core part in Franzese's courses. Within her courses, learning circles require that sudents know the name of every student in the class. By using these practices students can individually meet others in the course and respond to one another about a course related question. While these learning circles can be considered a contemplative approach, they also serve facilitate the incorporation of other contemplative pedagogies.
Another example of a partnership that is forged by using earning circles comes from an upper-level interdisciplinary course (not previously mentioned, but relevant here). That course regularly utilized learning circles and students developed great familiarity with one another.As the course unfolded, many of the students who were seniors had absences from the class due to job interviews. The course content focused on the science of happiness and connectedness and Franzese offered the mindful practice of sending good wishes for students who were absent for interviews. Franzese gained a sense that this 'took' when students anticipating absences began to ask if our class mindfulness practice could center on them, wishing them well. This was undoubtedly a pedagogical approach that was with students as they used it on their own and requested it (and in fact shared afterwards that they were thinking of the class members thinking of them during their interview). Similarly, in the upper level sociology

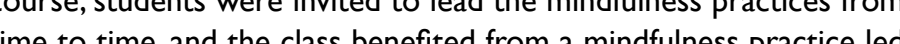
by a student well-versed in yea and a mindful listening practice led music selected by a student passionate about music. The learning circle approach facilited a sense of connectedness and partnership that paved the way for additional contemplative practices and approaches. While the implementation of the contemplative practices was conducted in partnership with students, so was the inquiry into the outcomes of these practices. As noted above, students began requesting contemplative practices and also took a meta-approach to their own learning providing unsolicited information about their level of attentiveness or focus on a given day, or how they implemented a 
contemplative practice.

Linking to the SoTL framework, the contemplative practices incorporated into Franzese's courses were consistently offered as invitations and included a communication that they were voluntary
practices. The Professor often also participated in these practices modeling the reflectiveness she was encouraging in her students. They were interactive with students, and in fact, the SoTL framework applied to contemplative pedagogy would support the idea of inviting member.

\section{Appropriately Public}

Having designed, implemented, and analyzed contemplative practices in her courses, Franzese has sought to share her experiences and insights with colleagues who might give her feedback or who might learn from her mistakes (and successes). First, Franzese gave a presentation on campus about contemplative writing. The purpose of this presentation was to share the state of the science about contemplative writing practices, invite faculty to reflect on contemplative practices they may already be incorporating, and allow faculty to identify new practices and consider how they might enace has been able to broaden her perspectives about the form and shape has been able to bres may take.
precong

Second, as a means to share findings about contemplative writing, Franzese presented about contemplative writing at a mindful campus conference at the University of North Carolina at Asheville. She engaged in this because she has attended the conference on a
few occasions and wanted both to contribute her knowledge about few occasions and wanted both to contribute her knowledge about
contemplative writing, and also have the experience of leading a contemplative writing practice with a audience of peers (some 30 other faculty/attendees). She observed that some faculty engaged in the practice excitedly while others had some reluctance - similar to a student group. This experience of in class related to the directions offered for the practice.

Finally, this article is written in that hopes that disclosing of Franzese's own successes and challenges will encourage others to share practices that they have used and create a contemplative practice exchange. She also is curious to learn about how others have assessed their practices. The specific contexts described here - local, regional, and more broadly - are appropriate because each uniquely serves a goal related to contemplative pedagogy, and they mirror the levels of SoTL outlined by Ashwin and Trigwell (2004). Local presentation allows for connection with university-level colleagues with shared interests. Regional presentation allows one to connect with others Finally, a journal article allows for more expansive consideration of a topic and facilitates exchange with distant colleagues.

Linking to the SoTL framework, the practice of utilizing contemplative practices was not done in isolation, but was approached in partnership with Franzese's university and with the wider acedemic community. In addition, there was a commitment to share the findings of the effort with colleagues both internal and external to the university, echoing Hutchings and Shulman's argument (1999) that SoTL serves both to improve an individual's teaching and to enhance the teaching commons.

\section{CONCLUSIONS: SOTL AS A CONTEMPLATIVE}

The practice of SoTL itself can be something of a contemplative practice. Doing SoTL is one way of mindfully focusing attention of a faculty member on the learning of her students. SoTL approaches at carefully inquire into learning, like some contemplative practices, help the faculty member to take a curious and open view of what is 列pening in the classroom. Student freewriting, for instance, allows We faculy member to witness what students are experiencing whout the need for guidance or graded evaluation. Other So TL approaches, on the other hand, focus a faculy member's vision on an issue of particular interest. Learning circles, for example, can effectively bring attention to the diversity that is present or missing feren fauly (and students) to be mindful about learning and teaching, an to discern deeper patterns and meaning than those that might be rent on the surface.

SoTL, of course, has its limitations. This framework guides the creation of inquiries that are firmly situated in particular contexts, making it difficult to generalize or replicate findings. SoTL also is nedodologically fluid, drawing on the expertise, epistemologies, allows many and diverse faculty to engage in SoTh it also wile this work up to critiques from social scientists who may have specialized methodologies that can be used to conduct similar reserch Duckworth \& Yeager 2015). Finally, SOTL and other analytical Dproaches often focus on snapshots or slices of learning rather tha on whole experiences. Since contemplative pedagogies often aim for integration and connection, this is a potential limitation that merits further exploration.

Like any heuristic, SoTL is imperfect, but we believe that on the whole it offers a framework that is well-suited for the aims of faculty (and others) inquiring into contemplative pedagogies and with the theory and practice of transformative learning 列 on questions within their locus of control - they ask their question about their students, use methods tied to their own expertise to explore those questions, and involve students and others in the process of makng sense of the results. In these ways, So TL effectively a goal of any educational inquiry by meeting the neds of faculy pracilioners who of contemplative pedagogies.

SoTL will never produce a single study that will scientifically prove the power and validity of contemplative pedagogies in higher education. However, if those of us who teach with contemplative pedagogies embrace the potential of SoTL, together we will build a and our institutions, to move closer to the heart of higher education.

\section{REFERENCES}

Ambrose, S. A., Bridges, M.W., DiPietro, M., Lovett, M. C., \& Norman, M. K. (2010). How learning works: 7 research-based principles for smart teaching. San Francisco, CA: Jossey-Bass.

Ashwin, P., \& Trigwell, K. (2004). Investigating staff and educationa development. In D. Baume \& P. Kahn (Eds.), Enhancing staff and educational development (Pp. | | Ka-|3|). London, UK. Routledge Falmer.

Barbezat, D. P., \& Bush, M. (2014). Contemplative practices in higher education: Powerful methods to transform teaching and learning. San Francisco, CA: Jossey-Bass.

Baugher,J.E. (2014). Contemplating uncomfortable emotions: Creating transformative spaces for learning in higher education. In $O$ Gunnlaugson, E.W. Sarath, C. Scott, \& H. Bai (Eds.), Contemplative learning and inquiry across disciplines (Pp. 233-252). Albany: State University of New York Press.

Chiesa,A., \& Serretti,A. (2009). Mindfulness-based stress reduction for stress management in healthy people:A review and meta-analysis.

Journal of Alternative \& Complementary Medicine, 15, 593-600.

Brown, J. (201 I). Contemplative pedagogy: Frequently asked Bro pedagogy: Frequen

Cook-Sather, A., Bovill, C., \& Felten, P. (2014). Engaging students as partners in learning and teaching: A guide for faculty. San Francisco, CA: Jossey-Bass.

Dencev, H., \& Collister, R. (2010).Authentic ways of knowing, authentic ways of being: Nurturing a Professional Community of Learn and Praxis. Journal of Transformative Education, 8(3), 178-196.

Assen, A. L., \& Yeager, D. S. (2015). Measurement matters: Assessing personal qualities other than cognitive ability
educational purposes. Educational Researcher, 44(4), 237-25I.

Felten, P. (2013). Principles of good practice in SoTL. Teaching \& Felten, P. (2013). Principles of good
Learning Inquiry, I ( I), I $121-125$.

Forni, P.M. (201I). The thinking life: How to thrive in the age of distraction. New York, NY: St. Martin's Press.

Franzese, A. T. (2009). Authenticity: Perspectives and experiences. In P. Vannini \& J. P.Williams (Eds.), Authenticity in culture, self, and society (pp. 87-10I). Burlington,VT:Ashgate.

Glisczinski, D.J. (2007). Transformative higher education:A meaningful degree of understanding. Journal of Transformative Education, 5(4) $317-328$

Grossman, P., Niemann, L., Schmidt, S., \& Walach, H. (2004) Mindfulness-based stress reduction and health benefits. A metaanalysis. Journal of Psychosomatic Research, 57, 35-43.

Gunnlaugson, O., Sarath, E. W., Scott, C., \& Bai, H. (Eds.) (2014). Contemplative learning and inquiry across disciplines (pp. 233-252) Albany: State University of New York Press.

Healey, M. Flint, A., \& Harrington, K. (2014). Engagement through partnership: Students as partners in learning and teaching in higher education. York, UK: Higher Education Academy.

Huber, M.T., \& Morreale, S. P. (2002). Disciplinary styles in the scholarship of teaching and learning: Exploring common ground. Washington, DC: American Association for Higher Education and The Carnegie Foundation for the Advancement of Teaching.

Hutchings, P., Huber, M. T., \& Ciccone, A. (201 I). The scholarship of teaching and learning reconsidered: In
impact. San Francisco, CA: Jossey-Bass.

Hutchings P. Kinzie, I \& Kuh, G. D. (2015). Evidence of sude Iering learning: What counts and what matters for improvement. In $G$. D. Kuh, S. O Ko Kunzie, Using Evidence of Student Caarning to Improve Higher Education (pp. 27-50). San Francisco, CA: Jossey-Bass.

Hutchings, P., \& Shulman, L. S. (1999). The scholarship of teaching: New elaborations, new developments. Change, 3I(5), 10-15.

Kabat-Zinn, J. (1990). Full catastrophe living: Using the wisdom of your body and mind to face stress, pain and illness. New York, NY: Del Publishing.
Kinney, K., ed. (2013). The scholarship of teaching and learning in and across the disciplines. Bloomington, IN: Indiana University Press. er, J.P. (2015). Contemplative education. [Special issue]. Journal of Transformative Education, virtual.

Guest editorial doi: 10.1 177//54/3446/5608465.

contemplative education Journal of thransformative Education. 13(3)
con, 197-218.

berski, I., Murray, S., Goldblatt, J., \& DePlacido, C. (2014). Contemplation \& mindfulness in higher education. In P.C. Layne \& P. Lake, eds., Global Innovation of Teaching and Learning in Higher Education (Pp. 317-340). New York: Springer.

Palmer, P. J., \& Zajonc, A., with Scribner, M. (2010). The heart of higher education: A call to renewal. San Francisco, CA: Jossey-Bass.

Paissman, S. (2008). Mindfulness-based stress reduction: A literature review and clinician's guide. Journal of the American Academy of Nurse Practitioners, 20(4), 212-216.

nini, P., \& Franzese, A. T. (2008). The authenticity of self: Conceptualization, personal experience, and practice. Sociology Compass, 2(5), 1621-1637.

Francisco, CA: Jossey-Bass.

Mefor America The mutud tronsormation of Buddhist medrtion and American culture Oxford Unive mation of 